\title{
THE CHINESE CONCEPT OF TALENTNESS IN THE IDEA OF NATIONAL PARAL YMPIC MOVEMENT
}

\author{
Nadiia Kalashnyk \\ Lviv Regional Institute for Public Administration of the National Academy \\ for Public Administration under the President of Ukraine, Ukraine \\ Andrei Marakushin \\ Simon Kuznets Kharkiv National University of Economics, Ukraine \\ Han Zhanglian \\ Lishui University, P.R.China \\ Wu Yanlin \\ Hanshan Pedagogical University, P.R.China \\ Nadiia Shevchenko \\ H.S.Skovoroda Kharkiv National Pedagogical University, Ukraine
}

\begin{abstract}
The idea of Paralympic movement is rather new for the Chinese society, though this country started its taking part in Paralympic games ' history in 1984. Traditionally the Chinese society was wary of people with physical disabilities seeing external flaws as a sign of personal inferiority and punishment of gods. The pure Chinese concept of talentness having as the basic tenet "there are no talented, there are those who are not very hardworking", also for a long time limited people with special needs in accessing sport events of a high (and even local) level. The idea of the article is to show the efforts of modern Chinese society in balance search between trends of Paralympic movement and Chinese traditional socio-psychological attitudes as to people with special needs. Such methods as interviewing, questioning, statistical data and official documents`analysis, analytic compilation were used. The following theoretical results were gained: as the Paralympic movement is not very strong in China due to its novelty, for today Paralympic athletes make up a small, almost closed group of Chinese athletes, where the criterion of talentness in a particular sport is leveled by the physical abilities and hardworking of each athlete in particular.
\end{abstract}

Keywords: athlete, China, Paralympics, people with special needs, sport, talentness.

\section{Introduction}

China is one of the countries that joined the Paralympic movement rather late (they first took part in Paralympic games in 1984) though for today gained great success at the Paralympic Games by topping the Paralympics medal table from the 2004 Summer Paralympics with a medal tally of over 1000 at 
Paralympics history. Also China initiated organization of Asian Para Games as an independent sport event that today is seen as not only as a high-level sport competition, but is also of great importance for Asian countries in overcoming cultural and social stereotypes in relation to people with disabilities According to President of the National Paralympic Committee of China Mr.Wang Xinxian, the Asian Para Games, these Chinese affords attract attention of government and society not only to people's with special needs opportunities and achievements, but also to their needs, problems, violation of their rights etc. (Cullum, 2016). The social development program of the PRC as a modern and progressive country also involves improving the country's external image in matters related to people with disabilities. These issues also come to the forefront in connection with the intensification of the PRC's work on the "One Belt, One Road" economic program with a huge social and cultural component. In order to be "on the level" with its foreign partners, China is obliged to pay attention to the issues connected with people with disabilities: improve their social status and social security on the state and local level, provide them with better educational and employment opportunities and much more (Beijing Sports University: "Belt and Road” Sports Talent program in China, 2017).

Though today China already hosted the Paralympics of 2008 and is ready for the Paralympics 2022, the idea of people with special physical needs take part in the activities like this is more the tribute to time and whole world trends than the conscious demand of the Chinese society. In one hand it is connected with the Chinese idea of superiority of the Chinese nation due to economic reasons and the Chinese tradition not to show their weaknesses (and having a person with special need was always treated as a weakness by the traditional Chinese society). The other reason can be seen in a specific concept of sport talent that is to be discovered to make a person be ready for the Paralympics and lack of specialist can make this talent be seen. The idea of the article is to show the efforts of modern Chinese society (as well as difficulties) in balance search between trends of Paralympic movement (which are being instilled into the Chinese modern society at the state level) and Chinese traditional socio-psychological attitudes as to people with special needs (that exist on the ground and determine the practice and effectiveness of government programs in this area). To gain the aim of the article such methods as interviewing of practicing trainers (during their vocational training course at Lishui University, sport department), questioning of parents (informal education training centers and private sports sections), statistical data and official documents`analysis (from the open courses), analytic compilation were used. 


\section{Analysis of the problem in the literature and main problematic}

Paralympic idea is quite new both for the Chinese society and scientific space. Firstly it appeared as a reality and the demand to the need to introduce the country in this section of international life as well and only now started to get some theoretical, analytical, methodological or educational background mainly thanks to efforts of abroad researchers and practicing athletes. The modern Chinese information in the media is reduced mainly to honoring the achievements of Chinese Paralympic athletes, taking into account their awards and state bonuses and using their achievements as a motivational basis for the nation as a whole. There are no publications of the Chinese researchers devoted to methods of training work with athletes with special needs, methods of the search for athletically gifted children with special needs and motivational work with them or parents in China yet neither in educational science or sport methodology one. Some ideas concern the problematic mentioned were found in the article of Chinese PhD program students of Hebei Normal University Li Xue and Wan Mo. Being majoring at sport as MA degree students, they make the analysis of nowadays problems of the training and educational system of athletes with special needs. The researchers come to the conclusion that for China for replenishment of the personnel reserve and work with potential Paralympic athletes (as highlevel professional athletes) it is better to resort with the help of foreign trainers from countries where the Paralympic movement has become widespread. This point of view is based on the issue that the system of working with such athletes has not only been formed, but also tested and brought results (such countries as Canada, US, GB, Ukraine are mentioned in particular) (Li \& Wan, 2018). Unfortunately their research has no information how to find up children with special needs who have some sport talent.

More information as to the needs and organization of educational and training work with athletes that have special needs can be found in interview to VICE (UK online magazine) and some publications of US and European athletes and trainers, especially those who took part at Paralympic games of 2008, 2018 and other sport events held for athletes with special needs in China. In particular, he mentions the following problems:

- $\quad$ lack of a specialized selection system for sports gifted children with special needs;

- $\quad$ lack of systemic work with sports gifted children with special needs organized and cared by the state;

- dominance of public interest (upholding the honor of the state) over personal growth and the needs for self-development of a person with special needs; 
- detachment from the idea of Paralympics in general and the need for additional attention for needs and unique opportunities of people with special needs in the minds of Chinese society (Cullum, 2016).

We shall try to represent the idea of talent concept traditional for the Chinese society influence over the modern situation with Paralympics in this country through the prism of problems mentioned above.

\section{The “Talent Concept” in China}

The traditional cultural and social views of the Chinese towards gifted people are based on the idea that talent (giftedness) is a gift from the gods (in the case of the Chinese, Heaven as the highest deity). The same Heaven concept, on the other hand, doesn't allow us to talk about talentness or giftedness of people with special needs. As in most cultures, external injuries or just a visual difference between a person and the standards of appearance accepted in a particular society (shorter or stature, albinism, heterochromia, etc.) were considered a punishment of gods and such a person became an outcast. Considering the external shortcomings of a person as his/her negative marking, the Chinese tried to avoid communicating with such people. But this concept applies only to those who had birth defects and do not apply to those who have been injured in wars or protecting their property, family, etc. In this case, the person was treated neutrally, but without the desire to establish close relations with him/her. Any mutilation happened to a person was a problem of his family and relatives, not of community or society, since any mutilation prevented a person from fulfilling his main social function: to work. Being an agrarian country, Chinese society almost always oriented its members to physical labor. Also, Chinese medical practices successfully eliminated most of the physical, mental and behavioral deviations that could be considered as disability in Europe. In this regard, even in the Middle Ages, the number of disabled people in the country was not large (in a percentage compared to Europe) and, as a rarity, caused mystical fear among common people. That's why in the history the Chinese could not (and until now mainly do not) accept the idea of having the Heaven's blessing at a person with special needs.

Through the history, the Chinese paid a lot of attention to talented people, though never made a system of search, selection and development. Talented people were more likely "nuggets" than a product of purposeful work and attention from the side of the Chinese state and society. Also unusual for Europeans has always remained the very perception of the concept of "talented" in traditional Chinese society. Unlike European culture, where a person who invented something was considered talented (painted a unique picture, composed beautiful original music, made a discovery), in China such a member of the society, which corresponded to the social ideal of society as much as possible was 
considered as talented (the social ideal of Chinese society remained almost unchanged from the most ancient times until the middle of the twentieth century).

Deriving the social image of the nation as "a nation sailing along the river forward, but sitting on a boat facing back", the Chinese have always seen the ideal in the past. Therefore, the task of subsequent generations has always been to maximize the copying of past achievements. In this case a talented person was expected to be a good imitator more, then a creator. The reflection of the issue mentioned can be illustrated by the following example: a talented student is one who manages equally well in all school subjects. Also as the measure of talent in the country's culture in the twentieth century for a long time remained the concept of hard work. "We don't have "talentless", we have those who are not hard working" - the slogan of the Chinese concept of talent for schools (including the art, music and dancing ones) in the twentieth century. (Kalashnyk, Burtseva, Naumenko, \& Wu, 2018)

Unfortunately such ideas are alive in the Chinese society till now. Discovering some talents in a child is the problem of his/her parents. Finding talented children is the problem of a teacher or a trainer. Maybe because having almost an unlimited human resource in all the spheres of life, China is not striving to create an integrated system of work with talented children. As before and today the state prefers to invest in an almost finished product, without spending money on startups. After the parents themselves take a child to a sports section (for example), pay for his/her classes, trips competitions, work with a coach who trains the child up to a certain level, the child wins several competitions at the provincial or national level, has got the experience of abroad competitions (usually organized by a trainer, paid by parents), then the child can get the opportunity to be selected for further training into a sports state boarding school. In this case helshe can have an opportunity to make a career as an athlete.

\section{State policy over athletes with special needs}

According to the Law of the People's Republic of China on the Protection of Disabled Persons (adopted in 1990), "a person with a disability is understood as the one who suffers from anomalies or loss of a certain organ or function psychologically or physiologically or in an anatomical structure, and who has completely or partially lost the ability to engage in any kind of ordinary activities in the usual way". (Law of the People's Republic of China on the Protection of Disabled Persons, 1990). According to the Constitution of the PRC, under term "people with disabilities" also see people with "visual, hearing, speech or physical disabilities, mental retardations, mental disorders, multiple disabilities and / or other irregularities» (The Constitution, 1990). Law of the People's Republic of China on the Protection of Disabled Persons guarantees the rights of people with 
disabilities as to education and employment opportunities, state and society responsibility towards them, rights and social guarantees of adequate level of care (Law of the People's Republic of China on the Protection of Disabled Persons, 1990). China ratified the UN Convention on the Rights of Persons with Disabilities in June 2008.

In 1988 was established China Disabled People Federation (CDPF) which mission is to promote the development of people with disabilities, to support their equal and full participation in public life, social, sports, materials and cultural achievements of modern Chinese society. (China Olympics official website, 2019)

The main institution of the country that forms the state policy towards athletes with special needs is China Administration of Sports for People with Disabilities (CASPD), which is also part of Central Government of China state apparatus. CASPD is a structural unit of China Disabled People Federation (CDPF) and is responsible for all issues related to the sport life of people with disabilities in the country, including professional sports for people with disabilities. The sphere of interests of this organization includes, in particular, the development of sports standards for athletes with disabilities, scientific and methodological research in the field of sports for disabled, selection of promising sports gifted children and adolescents with disabilities for further training in state sports boarding schools, formation of the PR China teams to participate in sports for people with disabilities of various levels including the Paralympic Games, etc. (Brief Introduction of CASPD, 2015). Also CASPD operates the China Disabled Sports Training Center (CDSTC) in Beijing - a sports complex specially equipped according to the latest technologies for people with disabilities, a training base for the Chinese Paralympic team in various sports except water ones (training centers for water sports are also run by the CASPD and located in Shanghai, Guangzhou, Shenzhen, Macau, Tianjin) (Xu, 2015).

The other half-state organization which is supported both by Chinese government and international organizations is "Special Olympics" which was found in Beijing in 1985. From the very first day, the Organization sees its mission in following: to conduct year-round sports training and sports competitions in various Olympic-type sports for children and adults with intellectual disabilities, to give them a constant opportunity to develop and maintain physical form, to demonstrate their abilities in the field of sports, to experience the joy of participating in competitions, friendship with other athletes, achieving goals, etc. For today the Organization already has 25 branches, 1,494,783 registered athletes and Unified partners and 75,517 coaches all over China (China Olympis official website, 2019).

Today, China is one of the most successful countries in Paralympic Games. In total, over the entire history of their participation, the national teams of the PRC 
have collected 1,000 medals, which is an absolute record for today. China also participates Deaflympics regularly and is one of the most successful nations there with the total amount of 99 medals. (China Deaflympics, 2017).

As one of peculiarities of the Chinese sport for disabled system can be recognized as a large component of non-formal education. As it was already mentioned, the state prefers to get involved in an almost guaranteed positive result and to maintain at the highest level the athletes who have already proved their competitiveness at a high level. The system of primary selection, primary training, as well as rehabilitation and reprofiling of athletes with disabilities usually lies in the field of informal (non-state) training and is funded through numerous NGOs, foundations, as well as through parents and sponsors of the athletes themselves. (Kalashnyk, Burtseva, Naumenko, \& Wu, 2018)

Thanks to its active participation in the Paralympic Games and the numerous victories that improve the country's external image, China is gradually changing both the country's infrastructure for people with disabilities and the attitude of the country's citizens towards such people. According to Qian Zhilin, a Beijing Normal University professor of special education, "thanks to Paralympic Games, the Chinese citizens are now actively learning about people with disabilities, and not, as before, reject them. The government in various ways teaches the population to see in disabled people equal members of modern Chinese society." (Tang, Zhang, \& Yang, 2014).

It may be said, that Chinese government make big, mainly financial, efforts to proclaim the idea of Paralympics in the country, to overcome the traditional views over talentless of people with disabilities and people with special needs. In one hand constant exaggeration of Chinese Paralympics athletes`achievements, stories on television and radio broadcasting about their lives and training before winning at the title international competitions, inclusion of stories about them and the Paralympic movement in general into school program, etc. which are held on the state level are waited to change the views of the Chinese about the possibilities and talents of disabled people. In the other hand China is a vast country and so the picture varies regionally. There are no universal standards for disability athletes ` benefit/support schemes, each province and city apply its own levels and standards.

\section{Gifted but not recognized: state programs` gabs, tradition and society attitude challenges}

Today the Chinese athletes with special needs also face challenges on their way to be recognized. As it was already mentioned, the main of them are: lack of a specialized selection system and systemic work with sports gifted children with special needs organized and cared by the state as well as detachment from the idea 
of people with special needs unique opportunities in the minds of the Chinese society.

According to state statistics, today China has about 65 million of disabled (Zhang, 2019). Because of this population size they can run a more rigorous training programme than the other countries can. If they lose 30, 40 or even 50 percent of their athletes on the way, China can still be left with enough athletes to compete. That forms a quite sharp competitiveness among this group of athletes as well. China puts the programmes in place for their athletes but they don't actually fund them until they succeed. When they succeed, they reward them with a life-changing sum of money not just for them but for their family for many generations to come (Cullum, 2016). It should be minded, that there are no special major at universities and other education establishments to educate the corp of Chinese trainers for work with disabled sports gifted children. The ones that work with them now (especially on the regional level) mainly are autodidacts that got their knowledge during their practical work and basic theory from abroad sources. The national-level disabled athletes mainly work with an "abroad+Chinese" coaches tandem or with the Chinese trainers who got their education from abroad professionals (Qiu, 2014). A lot of trainers who work at non-specialized training centers or schools (both private and municipal ones) are not ready to work with sports gifted disabled students neither psychologically nor methodically.

Here we show the results of two groups of coaches and trainers who got the vocational training course at Lishui University (Zhejiang province, PR China), Physical education department (spring and autumn semester 2019 academic year) interviewing. The groups consisted of 35 professional each. All the coaches had at least 5 years` experience of work and represent professionals working both at institutions of formal (sections and sport clubs sponsored and established by local government) and informal (private sports schools and sections, sports schools organized and financed by community or company individual private coaching etc.) education. The interview was anonymous and, according to the initiators of the survey, reflects the real situation as to work with sport gifted children and athletes with special needs in Chinese regions. The interview results are published for the first time. According to the Interview held:

1. $100 \%$ of the trainers would not like to have a sport gifted child with special needs among his/her pupils. The reasons mentioned:

- $\quad$ they need special attention and I am not ready for this;

- I was not trained to work with such children (or, as a variant, "only specially trained professionals should work with such children, better abroad ones");

- $\quad$ they need too much of my attention with the result too uncertain (though most of the trainers understood that if they really make good results 
with such a child they can make a good trainer`s career faster, but will have to change the specialization on work with disable gifted children. In the opinion of trainers, the balance between the efforts expended and the expected result is not observed);

- $\quad$ I can lose my other pupils because their parents are not ready to have a disabled child in the group.

2. Trainers mainly (93,7\%) would not like to have special training courses to be able to work with sport gifted children in future. Te reasons mentioned:

- I already have my specialty and my pupils and I am completely satisfied with the situation;

- I can't imagine a situation where this knowledge and skills could be useful to me (in my practice I never met parents of sport gifted children bring them to a regular sports section - usually they are initially looking for specialized schools, if deal with this question at all);

- $\quad$ there is not enough social request for this service;

- $\quad$ China has no specialists who can train me;

- I am not psychologically ready to communicate such children and deal with them day-by-day.

3. As to the question "Who should initiate a training work with sport gifted children with special needs (including search and selection, training, introduction to competitions)?", the following answers were got:

- $\quad$ state or local authorities (as they are interested in food image of China within the international sport society);

- local authorities and local state government as they get additional financing for this activity from the state;

- local government as they are interested in good image of the region to get more financing from the state;

- $\quad$ parents of such children;

- $\quad$ young trainers who graduated or not still graduated from Universities (explaining, that they still have no fixed specialization and set of pupils, so have "almost nothing to lose" but are interested in making a good career);

- NGOs and other social agencies, including the abroad ones.

As to the detachment from the idea of people with special needs unique opportunities in the minds of the Chinese society, the interview taken as the feedback to the research made and mentioned above by trainers themselves show, that only $10 \%$ of parents share the idea that children with special needs can be trained at ordinary sport schools and sections, but only 5\% of them stand for the idea that they can be trained together with the rest of the children. The reasons that parents express are: 
- a trainer will pay more attention to the child with disabilities at the expense of the rest of the children;

- don't want to put their children in a situation in which they have to compete or use physical force towards a person with special needs (this is especially true for power sports or martial arts);

- don't want their children to be emotionally involved into problems of people with special needs;

- $\quad$ such children should be trained in special way by specialized trainers.

The parents` interview results are published for the first time as well.

\section{Results}

For today, the traditional Chinese concept of talentness still influences the social views of the Chinese towards gifted people with special needs in general and sport gifted in particular. Unlike other countries, China still does not provide such children with comprehensive social support system, limiting by support and creation of conditions for those who independently achieved success at the initial and middle stages of becoming a professional. It can be explained by the size of the country, peculiarities of its social life ossification and the dynamism of economic development in the late twentieth and early 21st centuries. The problem that the Chinese face for today as to the educational and training work with sport gifted children with special need is the misbalance in state affords towards image on the international level and social views as to inferiority and unsuitability of this category of children and people in general. Due to the traditional Chinese social norm and behavior rules, Chinese society follows the path of not including people with special needs into the sports life of the region and a particular section. The Chinese society still needs time and planned educational and promotional work to overcome traditional social attitudes and change their worldview.

\section{References}

Beijing Sports University: “Belt and Road” Sports Talent program in China (2017). Retrieved from https://scholarship-positions.com/beijing-sports-university-belt-roadsports-talentscholarship-program-china/2017/12/25/

Brief Introduction of CASPD. (2015). Retrieved from https://en.wikipedia.org/wiki/China_ Administration_of_Sports_for_Persons_with_Disabilities

China Deaflympics. (2017). Retrieved from www.deaflympics.com

China Olympics official website. (2019). Retrieved from https://www.specialolympics.org/ programs/east-asia/china

Constitution of PR China. (1990). Retrieved from https:/www.purdue.edu/crcs/wpcontent/uploads/2014/04/Constitution.pdf 
Proceedings of the International Scientific Conference. Volume IV, May $22^{\text {th }}-23^{\text {th }}, 2020.232-242$

Cullum, B. (2016). Is China's Paralympic Dominance Reflected In Their Support For Disabled People? Retrieved from https://www.vice.com/en_uk/article/mgzb54/is-chinasparalympic-dominance-reflected-in-their-support-for-disabled-people

Kalashnyk, L., Burtseva, Y., Naumenko, S., \& Wu, Y. (2018). Informal component in the educational work with gifted children in China. Society. Integration. Education, 3. DOI: http://dx.doi.org/10.17770/sie2018vol1.3247

Law of the People's Republic of China on the Protection of Disabled Persons. (1990). Retrieved from https://www.ilo.org/dyn/natlex/docs/WEBTEXT/31906/64869/E90CHN01.htm

Li, X., \& Wan, M. (2018). Whom to give the future Paralympics winners for education to. Hebei Normal University Review, 1. Retrieved from https://wenku.baidu.com/view/ aa8a00ee68eae009581b6bd97f1922791788be61.html (in Chinese)

Qiu, Q. (2014). China shines a light on the disabled. China Daily. 30.10.

Tang, Zh., Zhang, Ch., \& Yang, X. (2014). Renovation of Existing Sport Venues in Guangzhou for Disable Access Prepared for the Asian Game. CNKI. 107.

Xu, Y. (2015). China's Paralympic Spirit. Beijing Review. 10.06.

Zhang, H. (2019). Paralympic games shows a friendly China for the disabled. Xinhua. August 28. 